\title{
TO THE 70TH BIRTHDAY OF ANDREI ALEKSEEVICH SLAVNOV
}

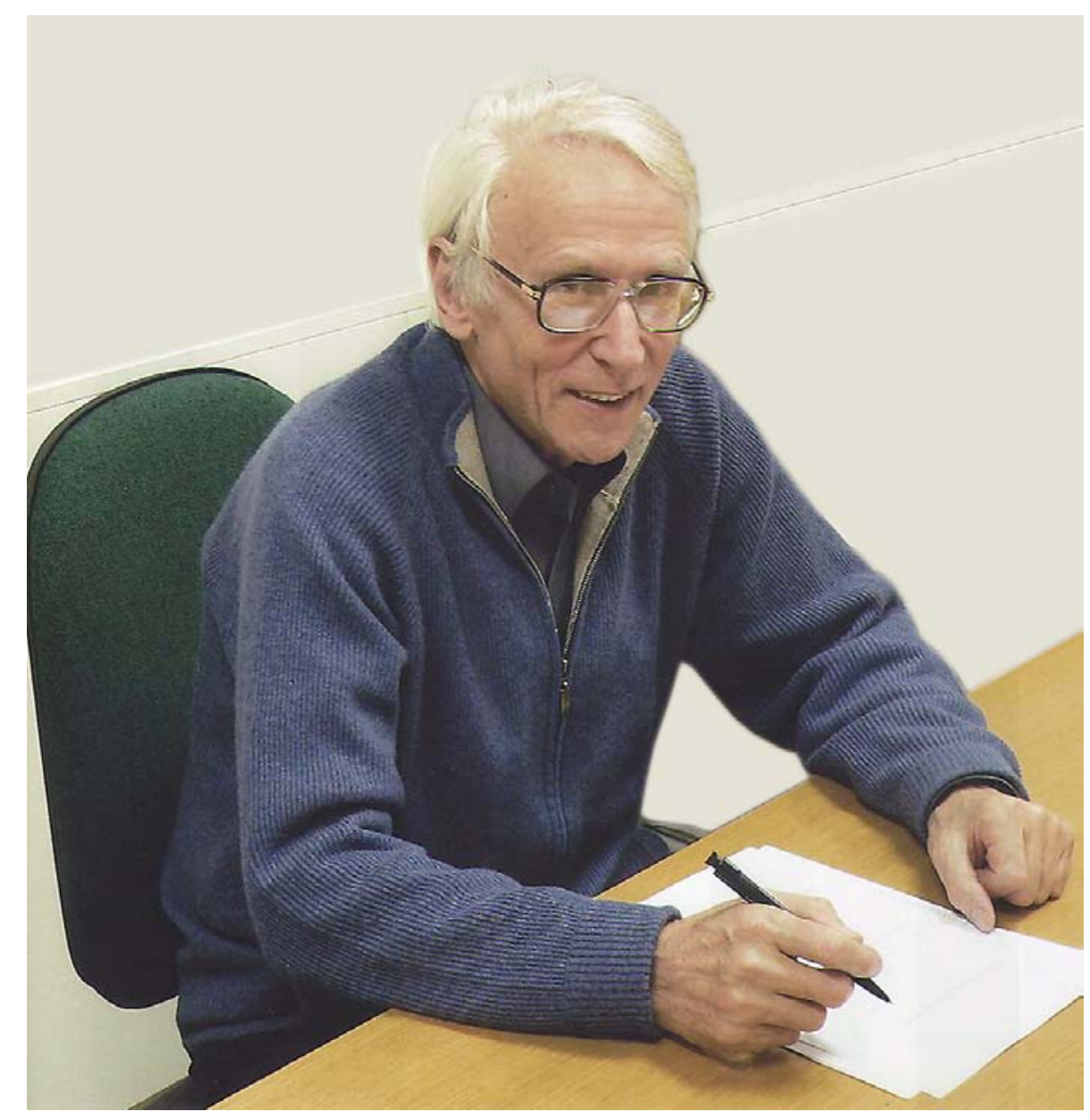

The members of the Editorial Board and staff of the journal

Theoretical and Mathematical Physics congratulate the First Deputy Editor-in-Chief

\section{Andrei Alekseevich Slavnov}

with his seventieth birthday and wish him

sound health, happiness, and further creative successes. 